\title{
Suppression of Grapevine Powdery Mildew by a Mycophagous Mite
}

\author{
Heather S. Melidossian and Robert C. Seem, Department of Plant Pathology, Greg English-Loeb, Department of \\ Entomology, and Wayne F. Wilcox and David M. Gadoury, Department of Plant Pathology, Cornell University, \\ New York State Agricultural Experiment Station, Geneva, NY 14456
}

\begin{abstract}
Melidossian, H. S., Seem, R. C., English-Loeb, G., Wilcox, W. F., and Gadoury, D. M. 2005.

Suppression of grapevine powdery mildew by a mycophagous mite. Plant Dis. 89:1331-1338.

Orthotydeus lambi reduced the severity of grape powdery mildew (Uncinula necator) on fruit and foliage of Vitis vinifera 'Chardonnay' and 'Riesling' in repeated field and laboratory trials. Vines were infested with $O$. lambi at two densities ( 5 or 30 mites per leaf) at each of two times ( 2 to 3 weeks prebloom and 1 week postbloom). Overall, powdery mildew on the berries and foliage was suppressed by early (prebloom) mite releases at both densities, but only by the higher density in late (postbloom) releases. In a separate trial, when foliage was infested at 30 mites per leaf but mites were excluded from certain fruit clusters, severity of powdery mildew was significantly reduced on the mite-free clusters of mite-infested shoots. Thus, $O$. lambi may suppress powdery mildew on the fruit by reducing inoculum from foliar infections. In laboratory studies, both immature and mature mites reduced infection efficiency, colony expansion, and sporulation of the mildew colonies; but immature mites were more voracious feeders, consuming more pathogen biomass per unit of mite biomass. Mites tore at the mycelium and conidia with their palps during feeding, leading to leakage, rapid loss of hyphal turgor, and collapse of hyphae.
\end{abstract}

Additional keywords: biological control, mycophagy, tritrophic interactions, tydeid mites

Grape powdery mildew, caused by the pathogen Uncinula necator (Schwein.) Burrill, is the most economically important disease of grapevine in the world and is found wherever grapes are cultivated (12). The pathogen infects all green tissues of the vine and is easily identified by the characteristic white, dusty appearance on the leaves, rachis, and foliage (13). Infection may result in decreased photosynthesis, reduced fruit quality, and an overall decline of vine health and vigor. Frequent and costly applications of fungicides are required to suppress the disease and minimize crop loss in most commercial production systems (13). Vitis species vary in levels of resistance to grape powdery mildew. The European wine grape (Vitis vinifera), comprising nearly all cultivars used for the production of fine wines, is highly susceptible to this pathogen (12). In the northeastern United States, managing powdery mildew has become increasingly difficult because the pathogen has developed resistance to both the sterol demethylation inhibitor (DMI) and strobilurin (QoL) fungicides (17). Although sulfur is widely used to control powdery mildew, it

Corresponding author: D. M. Gadoury

E-mail: dmg4@ cornell.edu

Accepted for publication 10 August 2005.

DOI: 10.1094/PD-89-1331

(C) 2005 The American Phytopathological Society often fails to provide adequate suppression of disease in cool, wet climates where powdery mildew can be especially severe (12). Furthermore, sulfur is phytotoxic to some varieties such as Vitis labruscana 'Concord' and is therefore unsuitable for application on this important processing cultivar. Biological control agents of grape powdery mildew, such as the fungal hyperparasite Ampelomyces quisqualis, have seen restricted commercial usage due to limited efficacy and high humidity requirements $(4,7)$. However, even partial disease control is likely to prove beneficial due to increased pathogen resistance to many fungicides. Moreover, moderately effective biological control agents may serve as important components of integrated pest management programs and mitigate the need to use fungicides.

Epiphytic mites in the family Tydeidae are mycophagous and graze on a variety of fungi and yeasts on the phylloplane $(14,15)$. English-Loeb et al. (3) identified a species (Orthotydeus lambi) that suppressed grape powdery mildew on potted Vitis riparia (riverbank grape) and $V$. vinifera vines. Little is known about the feeding habits and ecological role of this mite; however, it is common on the leaves of wild $V$. riparia, often exceeding densities of 100 mites per leaf (3). V. riparia appears to be relatively resistant to grape powdery mildew in the wild, with minimal foliar infection occurring on the canopy. However, the foliage of $V$. riparia is moderately susceptible to the pathogen under green- house conditions (12). Norton et al. (11) found that $O$. lambi was effective at suppressing powdery mildew on $V$. riparia in field trials, with the highest mite densities and greatest disease suppression occurring on vines with larger domatia, i.e., welldeveloped tufts of trichomes located at vein axils on the underside of leaves (14). $O$. lambi can also be found at relatively high densities on the leaves of several species of woody trees and shrubs that grow in the northeastern United States, including Norway maple, Acer platanoides, and apple, Malus pumila (11).

The studies by English-Loeb et al. (3) and Norton et al. (11) document one of the few known occurrences of an arthropod successfully controlling a plant pathogen (10). The tritrophic interactions between $O$. lambi, U. necator, and V. riparia also suggest a novel and potentially effective opportunity for biological control of powdery mildew on cultivated grapes. Surveys of mite populations in New York have shown that, whereas $O$. lambi is present at high densities on the foliage of wild $V$. riparia, it is virtually absent in many commercial plantings of various Vitis species and hybrids (3). This scarcity is attributed to the widespread use of carbaryl, mancozeb, and sulfur in commercial vineyards, which suppress natural populations of $O$. lambi $(2,9)$. Research on the use of alternatives to these materials, and the preservation of natural populations of $O$. lambi in commercial vineyards, is ongoing. However, further research also is required to clarify the interactions between $O$. lambi and U. necator and determine the mechanism by which the mites suppress disease. The objectives of this study were to determine: (i) how the presence of $O$. lambi retards colony growth of the pathogen; (ii) what part of the vegetative body is attacked and what is the nature of the damage to the fungal structures; (iii) the quantitative impact of $O$. lambi on epidemic progression; and (iv) when in the epidemic and in what numbers $O$. lambi must be present to exert a given degree of suppression.

\section{MATERIALS AND METHODS}

Effects of timing and density of mite releases on disease suppression in a vineyard. Field trials were conducted at a previously described (6) 1-ha experimental vineyard in Geneva, NY, planted in 1974 with $2.4 \mathrm{~m}$ between vines and $2.7 \mathrm{~m}$ between rows. Vines were Umbrella-Kniffen 
trained and cane pruned each year of the study. In 2001, vines of $V$. vinifera 'Chardonnay' were randomly assigned to receive the following treatments: (i) no mites; (ii) early releases of mites at densities of 5 mites per leaf; (iii) early releases of mites at 30 mites per leaf; (iv) late releases of mites at 5 mites per leaf; and (v) late releases of mites at 30 mites per leaf. Treatments were applied to three shoots per vine of single-vine plots, which were replicated three times. Shoots were inoculated at Eichhorn-Lorenz stage 12 (five to six unfolded leaves) (13) with an aqueous suspension of $10^{5}$ conidia per milliliter using inoculum from infected $V$. vinifera seedlings (6). The youngest three to four leaves per shoot were sprayed with the spore suspension using a hand-held atomizer until droplets of suspension were visible. Clusters were protected by small plastic bags during the process and were not inoculated. The viability of the conidial suspension was determined by placing one drop of suspension on a glass slide and counting the number of germinated conidia after $24 \mathrm{~h}$ of incubation in a moist chamber. The shoots were briefly covered with plastic bags as described by Gadoury et al. (6) when fungicides were applied to the remainder of the vineyard every 10 to 14 days. Only topical protectant and locally systemic fungicides with minimal vapor activity were applied during the experiments.

O. lambi were released onto the shoots 2 days after inoculation (17 days prebloom) and 28 days after inoculation (9 days postbloom) for the early and late releases, respectively. Mites were collected from wild $V$. riparia leaves growing in the vicinity and forced onto additional excised $\mathrm{V}$. riparia leaves using a Berlese funnel system (8). Mites were then transferred onto 2$\mathrm{cm}$-diameter $V$. riparia leaf disks using a fine brush and released onto the shoots by pinning the disks onto the underside of the leaves (one disk per leaf). Tanglefoot (Tanglefoot Company, Grand Rapids, MI), which serves as a physical barrier to arthropod movement, was applied with a plastic syringe around the base of all shoots to prevent the mites from leaving the shoots. Severity of powdery mildew infection was assessed every 2 weeks (on average), from 1 week postbloom until harvest, by visually estimating the percentage of foliar and fruit surface area covered with mycelia. Measurements were taken on all leaves and clusters. In addition, mite density was assessed on the foliage and clusters at 16 and 42 days postbloom. All leaves and clusters on the shoots were examined for the presence of $O$. lambi using $\times 10$ magnification Optivisors.

The experiment was repeated in 2002 with the following modifications: mites were released 2 days after inoculation (18 days prebloom) and 25 days after inoculation (5 days postbloom), and treatments were replicated six times. Disease severity was assessed approximately every 16 days from 2 days prebloom until harvest. Severity was quantified by visually estimating the percentage of surface area that was covered with mycelia for all clusters and every second leaf on the shoots, beginning with the basal leaf. Mite density was assessed on all clusters and five randomly selected leaves per shoot twice during the growing season, at 34 days and 81 days postbloom.

In 2003, 'Chardonnay' vines were randomly allocated to receive three treatments: (i) no mites; (ii) early releases of mites at densities of 5 per leaf; and (iii) early releases of mites at 30 per leaf. Treatments were applied to two shoots per vine of single-vine plots, which were replicated 10 times. Shoots were inoculated at Eichhorn-Lorenz stage 12, and mites were released the same day (20 days prebloom). Mite density was assessed at approximately 9-day intervals from 8 days prebloom until 26 days postbloom by randomly sampling four leaves per shoot. Severity of powdery mildew infection was measured on all clusters and every second to third leaf on the shoots starting with the basal leaf. Disease assessments were performed every 17 days (on average) from 8 days prebloom until 62 days postbloom. Mite density and disease severity were quantified following the methods described previously.

Treatment effects were compared on the foliage and fruit from 2001 to 2003 using SAS PROC MIXED (SAS Institute, Cary, NC, 1997) and One-Way ANOVA (SAS Institute, 2000), respectively. The slopes of the nontransformed foliar disease progress data were compared in order to contrast the effect of each treatment on epidemic progression throughout the growing season. The mean severity of powdery mildew on the fruit was compared at the end of the growing season using ANOVA $(\alpha=0.05)$.

Direct versus indirect impacts of $O$. lambi on fruit infection. Trials were set up in the same experimental vineyard to determine if disease suppression on the clusters was a direct result of mite feeding upon colonies growing on the clusters, or an indirect result of reduced sporulation from damaged mildew colonies on the foliage. $O$. lambi were released onto the foliage and selectively excluded from certain berry clusters by applying Tanglefoot around the peduncle. In 2002, four treatments were randomly allocated to vines of $V$. vinifera 'Riesling': (i) no mites with Tanglefoot around the peduncle; (ii) no mites without Tanglefoot; (iii) 30 mites per leaf with Tanglefoot around the peduncle; and (iv) 30 mites per leaf without Tanglefoot. Treatments were applied to two shoots per vine of split-vine plots that were replicated 13 times. The youngest three or four leaves per shoot were inoculated with an aqueous suspension of $10^{5}$ conidia per $\mathrm{ml}$ at Eichhorn-Lorenz stage 12, as before. Using the methods described previously, $O$. lambi was collected from wild V. riparia and released onto the foliage 1 day after inoculation (17 days prebloom), and Tanglefoot was applied around the peduncle of selected berry clusters and around the base of all shoots. Severity of powdery mildew infection was assessed as before on all clusters and every second leaf on the shoots starting with the basal leaf at approximate 16-day intervals from 16 days postbloom until harvest. Severity was quantified by visually estimating the percentage of the surface area that was covered with mycelia for all the clusters and every second leaf on the shoots starting with the basal leaf. Prevalence of $O$. lambi was assessed at 31 days and 79 days postbloom on all clusters and five randomly selected leaves per shoot, as described above. The experiment was repeated in 2003 with the following modifications: shoots were inoculated at Eichorn-Lorenz stage 15 (eight to 10 unfolded leaves), and mites were released the same day (14 days prebloom). Disease severity was assessed on all clusters and every second to third leaf on the shoots starting with the basal leaf at approximate 2-week intervals from 3 days prebloom until 62 days postbloom. Mite density was assessed at approximate 9-day intervals from 8 days prebloom until 26 days postbloom on all clusters and four randomly selected leaves per shoot. Disease severity and mite prevalence were quantified following the methods described previously.

Severity of powdery mildew on the clusters at harvest was compared among treatments in order to determine the relative effect of each treatment at suppressing disease on the fruit. Treatment effects were quantified using one-way ANOVA followed by comparison of means using Student's $t$ test $(\alpha=0.05)$.

Impact of $O$. lambi on colony growth and sporulation of $\boldsymbol{U}$. necator. Leaf disks, $2 \mathrm{~cm}$ diameter, were cut from young, susceptible leaves of unsprayed 'Chardonnay' vines grown in the greenhouse. The disks were surface-sterilized in a $10 \%$ bleach solution for $1 \mathrm{~min}$ and rinsed in distilled water for $1 \mathrm{~min}$. The disks were placed on wet cotton in petri plates to maintain leaf turgor and viability. The adaxial surface of each leaf disk was inoculated with two 3$\mu \mathrm{l}$ drops of an aqueous suspension of $10^{5}$ conidia per ml prepared from 2-week-old powdery mildew colonies on infected $V$. vinifera seedlings. The conidial suspension was prepared following the protocol of Gadoury et al. (6). The following treatments were randomly assigned to leaf disks: (i) no mites; (ii) application of mites 1 day before inoculation; (iii) application of mites 1 day after inoculation; and (iv) application of mites 2 days after inoculation. Adult mites were transferred onto the leaf disks at a density of 10 mites per disk 
using a fine brush, and treatments were replicated 10 times. O. lambi was originally collected from wild $V$. riparia and laboratory reared on a diet of cattail (Typhus sp.) pollen. The population was maintained in a controlled environment at $25^{\circ} \mathrm{C} / 55 \%$ relative humidity with a regime of $16 \mathrm{~h}$ light and $8 \mathrm{~h}$ dark. To maintain the density of mites at 10 per leaf disk, healthy adult mites from the laboratory population were used to replace any that died during the experiment, which approximated 50\% of the total population by the end. The diameter of the resultant mildew colonies was measured every 2 to 3 days using a dissecting scope equipped with an ocular micrometer. After 14 days, the mites were removed from the disks, and the disks were placed in $2 \mathrm{ml}$ of distilled water in separate vials. The vials were shaken vigorously for $10 \mathrm{~s}$ in order to release conidia from the conidiophores, and the number of conidia per $\mathrm{ml}$ of suspension was determined using a hemacytometer. The number of conidia per $\mathrm{mm}^{2}$ of leaf tissue was then calculated. The experiment was subsequently repeated with the following modifications: leaf disks were inoculated with one 6- $\mu$ l drop of spore solution and were randomly allocated to the following treatments: (i) no mites; (ii) application of mites 1 day before inoculation; (iii) application of mites 1 day after inoculation; (iv) application of mites 7 days after inoculation; and (v) application of mites 10 days after inoculation. The diameter of the resultant mildew colonies was measured every 5 days. After 19 days, the mites were removed from the disks and sporulation calculated as conidia per $\mathrm{mm}^{2}$ of leaf tissue as described previously. Treatment effects were analyzed using One-Way ANOVA followed by comparison of means using Student's $t$ test $(\alpha=0.05)$.

Comparative effects of adult and immature $O$. lambi on colony growth and sporulation of $\boldsymbol{U}$. necator. Leaf disks from young 'Chardonnay' vines grown in the greenhouse were prepared as described above. The adaxial surface of each leaf disk was inoculated with one 5- $\mu$ l drop of an aqueous suspension of $10^{5}$ conidia per $\mathrm{ml}$ as before. Leaf disks were randomly allocated to the following treatments: (i) no mites; (ii) adult mites applied 1 day after inoculation; and (iii) immature (protonymph) mites applied 1 day after inoculation. Mites were applied at a density of 10 per disk using a fine brush, and each treatment was replicated 10 times. Source and rearing conditions for $O$. lambi were the same as described previously. To retain the density of mites at 10 per disk, healthy adult and protonymph mites from the laboratory population were used to replace any that died during the experiment; replacements approximated $50 \%$ of the original population by the end of the trial. The diameter of the resultant mildew colonies was measured every 3 days as before. After 21 days, the mites were removed from the disks, and the disks were placed into $2 \mathrm{ml}$ of distilled water in separate vials. The vials were shaken vigorously for $10 \mathrm{~s}$ in order to release conidia from the conidiophores, and the number of conidia per $\mathrm{ml}$ of suspension was determined using a hemacytometer. Sporulation of the mildew colonies, measured as conidia per $\mathrm{mm}^{2}$ of leaf tissue, was calculated as before. The experiment was repeated, and treatment effects were analyzed using One-Way ANOVA followed by comparison of means using Student's $t$ test $(\alpha=0.05)$.

Microscopic observations of $O$. lambi feeding behavior. A variety of microscopy techniques were utilized in order to determine how $O$. lambi physically damages powdery mildew colonies, resulting in observed disease suppression. Leaf disks, collected from 'Chardonnay' vines grown in the greenhouse, were prepared as described previously. Adult and immature $O$. lambi were applied to the leaf disks at a density of 10 individuals per disk and starved for $48 \mathrm{~h}$. The adaxial surface of each leaf disk was then inoculated with one 4- $\mu$ l drop of a conidial suspension $\left(10^{5}\right.$ conidia per $\mathrm{ml})$. Each treatment was replicated five times, and the experiment was repeated twice. The feeding behavior of the mites was monitored at 5- or 10-min intervals under a dissecting microscope at $\times 35$. Behaviors recorded were: (i) number of mites feeding; (ii) duration of mite feeding; and (iii) physical movements and actions that indicated a feeding response.

To gain a better understanding of the mechanics of mite feeding, five immature tydeids were placed on glass microscope slides that had been dusted with conidia the previous day. Mites were prevented from moving off the slides by applying Tanglefoot around the perimeter. Mite feeding behavior and subsequent fungal damage was observed under epiluminescence microscopy.

To observe the mites using scanning electron microscopy, young adult and immature $O$. lambi were placed onto the adaxial surface of 'Chardonnay' leaf disks at a density of seven mites per disk and allowed to feed on 3-day-old mildew colo-

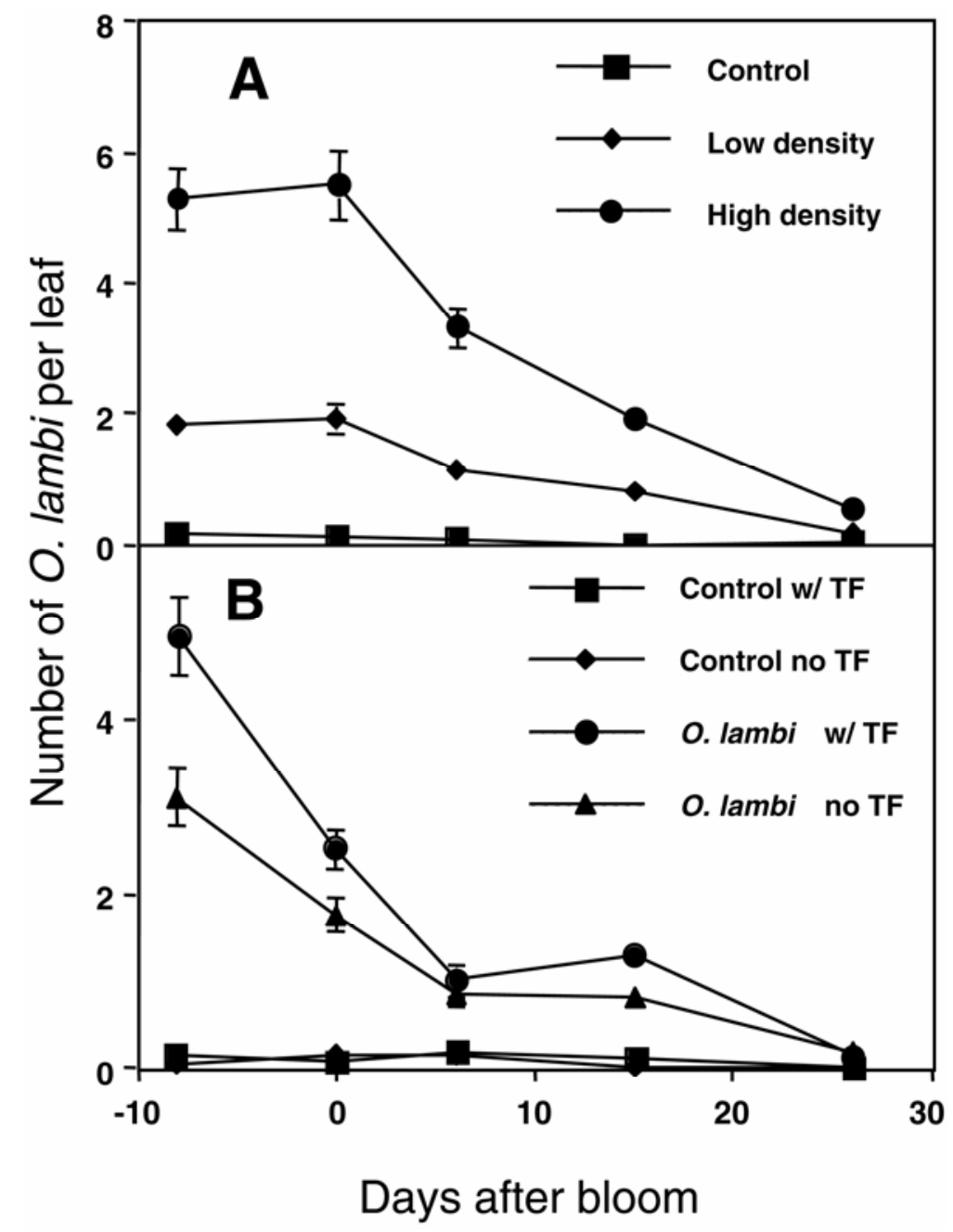

Fig. 1. Mean density per leaf of Orthotydeus lambi on A, 'Chardonnay' and B, 'Riesling' shoots on various days after bloom in 2003. A, Mites applied at densities of 5 and 30 mites per leaf at 3 weeks prebloom. B, Mites applied at densities of 30 mites per leaf at 2 weeks prebloom. TF $=$ Tanglefoot applied around the peduncle. Vertical bars indicate one standard error of the mean. 
nies for 2 to 3 h. O. lambi were collected and applied to the leaf disks as described previously. The precise locations on the hypha or conidia where $O$. lambi grazed were observed at $\times 35$ and photographically the leaf samples were immediately fixed in $1 \%$ aqueous osmium tetraoxide overnight at room temperature, dehydrated in a graded ethyl alcohol series, critical-point dried, and coated with gold-palladium. The a scanning electron microscope (SEM) for signs of mechanical damage to the fungal thallus. The procedure was repeated twice.

\section{RESULTS}

Density of $O$. lambi on the fruit and foliage. Populations of $O$. lambi declined from their original release densities in all 3 years of field trials. In 2001, mite densities on 'Chardonnay' declined from prebloom release densities of 5 and 30 mites per leaf to $0.49(\mathrm{SE}=0.10)$ and $2.20(\mathrm{SE}=0.30)$, respectively, by 6 weeks postbloom (9 weeks postrelease). Postbloom releases of O. lambi declined to $1.97(\mathrm{SE}=0.30)$ and $3.75(\mathrm{SE}=0.47)$ mites per leaf for low and high releases, respectively, by 6 weeks recorded. Once the mites were removed, fixed specimens were then observed under

postbloom (5 weeks postrelease). No mites were observed on the clusters at any time in 2001. In 2002, prebloom releases of $O$. lambi had declined to $0.37(\mathrm{SE}=0.09)$ and $2.20(\mathrm{SE}=0.29)$ mites per leaf for low and high releases, respectively, by 5 weeks postbloom (8 weeks postrelease). Postbloom releases of 5 and 30 mites per leaf declined to $0.83(\mathrm{SE}=0.13)$ and 2.44 (SE $=0.34$ ), respectively, by 5 weeks postbloom (4 weeks postrelease). At 11 weeks postbloom, when the second count was performed, $O$. lambi were present at trace levels on the foliage. Prebloom releases declined to $0.14(\mathrm{SE}=0.05)$ and 0.81 (SE $=0.18$ ) mites per leaf (14 weeks postrelease), and postbloom releases declined to $0.56(\mathrm{SE}=0.19)$ and $0.35(\mathrm{SE}=0.09)$ mites per leaf (10 weeks postrelease) for low and high releases, respectively. No mites were observed on the clusters at any time. In 2003, mite populations declined from release densities to $0.17(\mathrm{SE}=0.05)$ and $0.52(\mathrm{SE}=0.15)$ mites per leaf for low and high releases, respectively, by the final count (4 weeks postbloom) (7 weeks postrelease) (Fig. 1). Again, no mites were present on the clusters throughout the season.

Table 1. Mixed model analysis of variance examining the effects of treatment, days after bloom, and interaction on foliar disease severity throughout the growing season in 2001 to 2003

\begin{tabular}{llccc}
\hline Year & Source $^{\mathbf{a}}$ & df & Type III F & $\boldsymbol{P}>\boldsymbol{F}$ \\
\hline 2001 & Treatment & 10 & 0.04 & 0.9967 \\
& Days after bloom (DAB) & 70 & 241.76 & 0.001 \\
& DAB*treatment & 70 & 4.15 & 0.0045 \\
2002 & Treatment & 25 & 0.43 & 0.7823 \\
& DAB & 115 & 124.42 & 0.0001 \\
& DAB*treatment & 115 & 1.83 & 0.1284 \\
2003 & Treatment & 27 & 0.34 & 0.7118 \\
& DAB & 87 & 193.61 & 0.0001 \\
& DAB*treatment & 87 & 5.71 & 0.0047 \\
\hline
\end{tabular}

${ }^{a}$ Treatments assessed were: (i) no mites; (ii) 5 mites per leaf released 3 weeks prebloom; (iii) 30 mites per leaf released 3 weeks prebloom; (iv) 5 mites per leaf released 1 week postbloom; and (v) 30 mites per leaf released 1 week postbloom. No postbloom releases in 2003.

Table 2. Mean surface area of 'Chardonnay' clusters covered with powdery mildew at harvest from 2001 to 2003

\begin{tabular}{llc}
\hline Year & Treatment $^{\mathbf{a}}$ & Fruit severity $^{\mathbf{b}}$ \\
\hline 2001 & Control & $7.00(2.37)$ \\
& Low release/3 weeks prebloom & $3.44(2.61)$ \\
& High release/3 weeks prebloom & $0.67(0.19)$ \\
& Low release/1 week postbloom & $7.22(3.56)$ \\
2002 & High release/1week postbloom & $3.33(2.04)$ \\
& Control & $41.47(5.29)$ \\
& Low release/3 weeks prebloom & $15.39(3.82)$ \\
& High release/3 weeks prebloom & $21.22(10.78)$ \\
& Low release/1 week postbloom & $35.83(11.75)$ \\
$2003^{c}$ & High release/1week postbloom & $12.67(8.01)$ \\
& Control & $90.17(3.35)$ \\
& Low release/3 weeks prebloom & $88.65(3.42)$ \\
& High release/3 weeks prebloom & $75.17(6.98)$
\end{tabular}

a Treatments assessed were: (i) no mites; (ii) 5 mites per leaf released 3 weeks prebloom; (iii) 30 mites per leaf released 3 weeks prebloom; (iv) 5 mites per leaf released 1 week postbloom; and (v) 30 mites per leaf released 1 week postbloom.

${ }^{\mathrm{b}}$ Severity was assessed as mean percent surface area of the berries visibly covered with mycelia. Standard errors are in parentheses. Severity values were assessed in 2001 at 58 days postbloom; in 2002 at 80 days postbloom; and in 2003 at 62 days postbloom.

c No postbloom releases in 2003.
Populations of $O$. lambi also declined on 'Riesling' shoots in 2002 and 2003. In 2002, mean numbers of mites declined from original release densities of 30 mites per leaf to $3.54(\mathrm{SE}=0.73)$ and $1.82(\mathrm{SE}=$ 0.33 ) for Tanglefoot and no Tanglefoot treatments, respectively, by 4 weeks postbloom (7 weeks postrelease). Populations continued to decline to trace levels by 11 weeks postbloom (14 weeks postrelease) to $0.02(\mathrm{SE}=0.02)$ and $0.18(\mathrm{SE}=0.10)$ mites per leaf, respectively. In 2003, populations of $O$. lambi declined by almost $100 \%$ based on the final count performed at 4 weeks postbloom (6 weeks postrelease) (Fig. 1). Mite densities declined from an average of 30 mites per leaf for both Tanglefoot and no Tanglefoot treatments to 0.17 $(\mathrm{SE}=0.06)$ and $0.19(\mathrm{SE}=0.10)$, respectively. $O$. lambi were found at nil to trace levels on the clusters for both years.

Effects of $O$. lambi release timing and density on disease suppression. Prebloom and high-density releases of $O$. lambi partially suppressed powdery mildew severity on the fruit and foliage in an experimental vineyard of $V$. vinifera 'Chardonnay' from 2001 to 2003. In 2001, prebloom releases of both 5 and 30 mites per leaf reduced the rate of foliar disease progress relative to the control and postbloom releases $(F=$ 4.15; $P=0.005$ ) (Mixed-Model SAS) (Table 1). Prebloom releases of $O$. lambi at both densities and postbloom releases of 30 mites per leaf also suppressed cluster severity at harvest, with the greatest disease suppression occurring on clusters that received the prebloom release of 30 mites per leaf $(<1 \%$ surface area infected; $\mathrm{SE}=$ $0.19)$. Although there was a clear trend of reduced disease for these treatments, differences in disease severity on the clusters did not differ statistically from the control ( $F=1.31 ; P=0.33$ ) (One-Way ANOVA) (Table 2). In 2002, both prebloom and postbloom releases of $O$. lambi at 30 individuals per leaf reduced the rates of foliar disease progress on the shoots relative to early and late releases of 5 mites per leaf and the control $(F=1.83 ; P=0.13)$ (Mixed-Model SAS) (Table 1). Mean cluster severity at harvest was suppressed by both high-density releases and the prebloom release of 5 mites per leaf $(F=$ 2.24; $P=0.09$ ) (One-Way ANOVA and Student's $t$ test, $\alpha=0.05)$. However, superior disease suppression was recorded on clusters receiving the postbloom release of 30 mites per leaf $(12.67 \%$ surface area infected; SE = 8.01) (Table 2). In 2003, releases of $O$. lambi at 30 individuals per leaf suppressed both the rate of foliar disease progress $(F=5.71 ; P=0.005)$ (Mixed-Model SAS) (Table 1) and cluster severity at harvest $(F=2.89 ; P=0.07)$ (One-Way ANOVA; Student's $t$ test, $\alpha=$ $0.05)$ relative to the control and prebloom release of 5 mites per leaf (Table 2).

Direct versus indirect impacts of $O$. lambi on disease development on fruit 
clusters. Releases of $O$. lambi at a density of 30 mites per leaf suppressed powdery mildew on 'Riesling' clusters in 2002 and 2003. No significant differences were observed in cluster severity between treatments that excluded mites from the berries with Tanglefoot and treatments that did not exclude them (Student's $t$ test, $\alpha=0.05$ ). Disease was suppressed on the clusters by all mite treatments compared with the controls $(F=3.19 ; P=0.03$ and $F=3.80$; $P=0.02$ ) (One-Way ANOVA) for both years, respectively (Table 3 ). In addition, there were no significant differences in cluster severity between the controls with and without Tanglefoot around the peduncle (Student's $t$ test, $\alpha=0.05$ ), indicating no suppressive effect of Tanglefoot application on powdery mildew severity.

Effects of $O$. lambi on colony expansion and sporulation. $O$. lambi reduced growth and sporulation of powdery mildew colonies on $V$. vinifera leaf disks in laboratory studies. In the first trial, colonies that received applications of mature $O$. lambi 1 day before or 1 or 2 days after powdery mildew inoculation had reduced expansion and sporulation $(P<0.0001)$ (One-Way ANOVA) compared with the control within the first 14 days of growth (Fig. 2A). In the second trial, treatments that received applications of $O$. lambi 1 day before and up to 10 days after inoculation also had reduced growth and sporulation (Fig. 2B) compared with the control $(P<$ 0.0001 , One-Way ANOVA). The greatest suppression of disease (Student's $t$ test, $\alpha$ $=0.05$ ) was consistently observed when $O$. lambi was applied 1 day before inoculation (Fig. 2). Adult and immature tydeids were equally effective (Fig. 3) at suppressing growth and sporulation of powdery mildew colonies when released onto $V$. vinifera leaf disks 1 day after inoculation (Student's $t$ test, $\alpha=0.05$ ). Mildew colonies that received applications of immature and adult $O$. lambi had significantly reduced expansion and sporulation within the first 18 days of growth compared with the control $(P<0.0001$, One-Way ANOVA).

Feeding behavior of $O$. lambi and damage to the fungal thallus. Adult and immature $O$. lambi exhibited a distinctive "feeding response" when in the presence of conidia and hyphae of $U$. necator. The mites typically paused at hyphae, conidia, and conidiophores and rapidly moved their palps along the surface of the structure in a motion that resembled clawing or scratching. O. lambi remained at a single location and fed upon the mildew colony for periods of up to $5 \mathrm{~min}$ uninterrupted, grazed quickly (10 to $20 \mathrm{~s}$ ), or ignored the fungus altogether. The feeding response under laboratory conditions was sporadic, although immature $O$. lambi often grazed for longer intervals and more frequently than the adult mites.

Hyphae and conidia that were exposed to $O$. lambi appeared collapsed and shrunken when viewed under SEM, whereas unexposed hyphae were turgid and undamaged (Fig. 4). No clearly identifiable signs of mouth-part damage, such as

stylet puncture holes or tearing by the palps, were observed. Under epiluminescence microscopy, feeding upon germinated conidia was immediately followed

Table 3. Mean surface area of 'Riesling' clusters covered with powdery mildew at harvest in 2002 to 2003

\begin{tabular}{llr}
\hline Year & Treatment $^{\mathbf{a}}$ & Fruit severity $^{\mathbf{b}}$ \\
\hline 2002 & Control + Tanglefoot & $10.77(5.65)$ \\
& Control (no Tanglefoot) & $18.50(6.82)$ \\
& Orthotydeus lambi + Tanglefoot & $1.65(1.14)$ \\
& O. lambi (no Tanglefoot) & $1.96(1.18)$ \\
2003 & Control + Tanglefoot & $68.96(6.75)$ \\
& Control (no Tanglefoot) & $74.36(6.71)$ \\
& O. lambi + Tanglefoot & $47.92(6.68)$ \\
& O. lambi (no Tanglefoot) & $50.71(6.44)$ \\
\hline
\end{tabular}

a Treatments assessed were: (i) no mites with and without Tanglefoot around the peduncle and (ii) 30 mites per leaf applied 2 to 3 weeks prebloom, with and without Tanglefoot around the peduncle.

${ }^{\mathrm{b}}$ Severity was measured as mean percent surface area of berries visibly covered with mycelia. Standard errors are in parentheses. Severity values were measured in 2002 at 59 days postbloom and in 2003 at 62 days postbloom.



Fig. 2. Sporulation and area of powdery mildew colonies on Vitis vinifera leaf disks. A, Adult tydeids applied at densities of 10 individuals per disk 1 day before powdery mildew inoculation and 1 to 2 days postinoculation for trial 1 . Sporulation and colony area were calculated after 14 days of growth. B, Adults tydeids applied at densities of 10 individuals per disk 1 day before inoculation and 1, 7, and 10 days after inoculation for trial 2. Sporulation and colony area were calculated after 18 days of growth. Vertical bars are equal to one standard error of the mean. 
by the droplets of the cellular contents on the hyphal surface, and within $10 \mathrm{~min}$ by the gradual deflation and collapse of the hyphal strand at the feeding site.

\section{DISCUSSION}

$O$. lambi partially suppressed powdery mildew on the foliage and fruit of $V$. vinifera cultivars for three consecutive years of field trials. On 'Riesling' vines, $O$. lambi reduced disease severity on the clusters by equivalent proportions regardless of whether they were excluded from the clusters by Tanglefoot or allowed access to move onto the clusters. Therefore, there was no additional suppressive effect by allowing the mites to move onto the clusters. Even when permitted to move freely onto the berries, $O$. lambi was found at nil to trace levels on the clusters in all surveys of mite density. Thus, when applied to the foliage but excluded from the berry clusters, $O$. lambi apparently suppressed disease severity on the fruit by damaging mildew colonies on the foliage. At present, there is no evidence of systemic acquired resistance in grapevines that may provide additional resistance to powdery mildew (18). Thus, the presence of $O$. lambi on the foliage does not appear to elicit a defense response in the berries. Moreover, $O$. lambi is an epiphytic mite and does not damage or wound the grapevine tissue in any discernible way that might induce a systemic defense response. Given the type of feeding damage observed in our laboratory studies, it appears that $O$. lambi remains upon the foliage and reduces the severity of disease on the clusters by mechanically damaging the fungal colonies on the leaves, thereby reducing the capacity of these colonies to serve as inoculum sources for infection of fruit.

On 'Chardonnay' vines, prebloom releases of $O$. lambi at both 5 and 30 individuals per leaf suppressed disease, but only releases of $30 \mathrm{O}$. lambi per leaf were suppressive when released postbloom. These results suggest that the timing of mite applications is more critical than absolute densities of mites per leaf, within the range of our releases, at suppressing powdery mildew on grapevines. The suppressive effects of early applications and high-density releases of mites appear to be additive, due to the fact that the prebloom, high-density releases of mites were consistently more suppressive than the other treatments throughout this study.

It is important to note that high disease pressure was created on the experimental shoots due to inoculations of spore suspension in conjunction with naturally occurring inoculum present in the vineyard, especially in 2002 and 2003. Thus, postbloom releases of $O$. lambi ( 3 to 4 weeks postinoculation) at 30 individuals per leaf were able to effectively suppress fruit and foliar mildew under extreme disease pressure that would not always be observed in natural systems.

Effective management practices for controlling powdery mildew in commercial vineyards require that prebloom and early postbloom disease be effectively suppressed until clusters develop ontogenic resistance at approximately 3 weeks postbloom in New York $(5,6)$. Pre- and postbloom presence of mites at high densities both appear to have potential to suppress disease during this critical period of berry susceptibility to powdery mildew. The brief window of susceptibility, and the presence of the mites during that critical period, may partially explain why the severity of disease on the clusters remained low for the most effective treatments, even when foliar disease became severe by the end of the season.

Suppression of disease on the foliage may have abated later in the growing season due to the decline of populations of $O$.

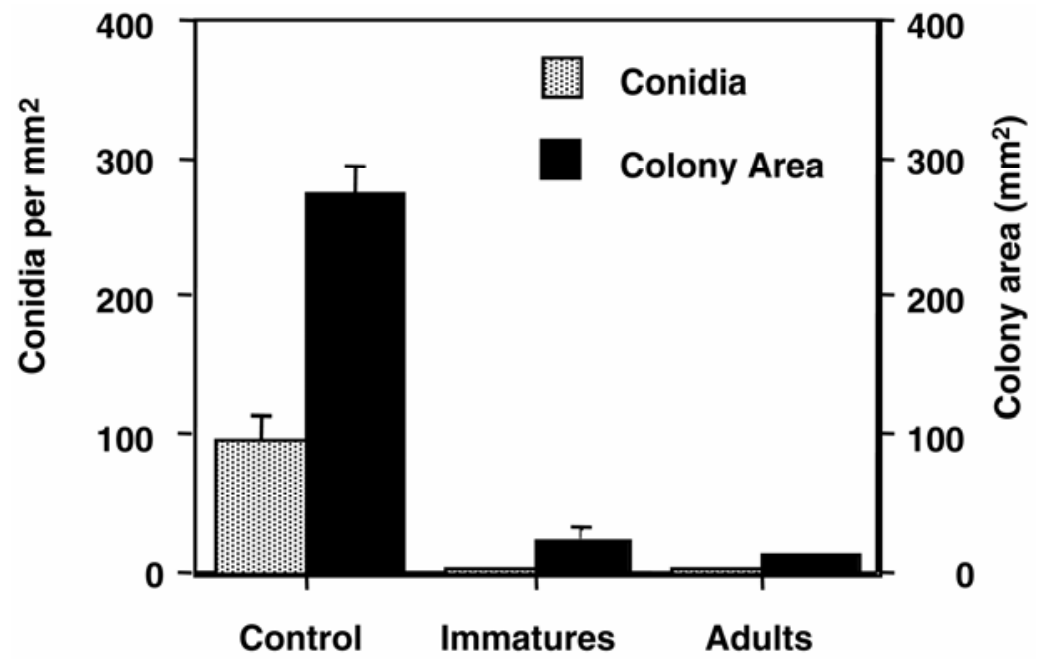

Fig. 3. Sporulation and area of powdery mildew colonies after 18 days of growth on Vitis vinifera leaf disks. Adult and immature Orthotydeus lambi applied at densities of 10 individuals per disk 1 day after inoculation. Bars indicate 1 standard error of the mean.

lambi from their original release densities in all 3 years of field trials (Fig. 1). The average number of mites per leaf at midseason and harvest declined to $<1$ in 2002 and 2003, even for treatments that received releases of 30 mites per leaf. Although mean densities of 1.6 to 3.8 mites per leaf have been shown to suppress disease on $V$. vinifera vines in greenhouse and field studies (3), greater suppression would probably have been achieved in this experiment if mean densities of $O$. lambi had remained at higher levels.

The cause of decline in mite populations in the field trials remains unknown, but may be related to our placing plastic bags around the shoots during spray applications to exclude fungicide residues. Tanglefoot applications around the bases of all the experimental shoots prevented $O$. lambi from moving off the shoots, thereby restricting them to the foliage on which they were applied. Thus, O. lambi populations did not decline due to migration off the shoots. Preliminary results in controlled-environment chambers show that $O$. lambi is killed when exposed to high relative humidity coupled with temperatures of $40^{\circ} \mathrm{C}$ or more for 2 to $3 \mathrm{~h}(\mathrm{H}$. S. Melidossian, unpublished data). Similar conditions may have developed inside the plastic bags during hot days, resulting in extensive mortality to the mites on the shoots. For example, data loggers affixed to $V$. riparia shoots and covered with plastic bags on warm days recorded temperatures up to 40 to $50^{\circ} \mathrm{C}$ for $3 \mathrm{~h}$ inside the bags (H. S. Melidossian, unpublished data). Based on our data, these temperatures are lethal to $O$. lambi.

$O$. lambi is effective at reducing critical fitness aspects of the pathogen such as colony growth and sporulation. Even when released up to 10 days after inoculation, $O$. lambi suppressed growth and sporulation of the mildew colonies on $V$. vinifera leaf disks (Fig. 2). However, greater disease suppression was achieved when the mites were released before or shortly after inoculation. Our lab results suggest that $O$. lambi is more effective at suppressing powdery mildew when allowed to graze on the fungus during the early phases of pathogen development, such as during initial conidial germination and before the onset of sporulation. In addition, disease suppression is not strictly limited to adult $O$. lambi. Immature (protonymph) $O$. lambi displayed comparable efficacy at suppressing growth and sporulation of the mildew colonies in laboratory trials (Fig. 3). Microscopic observations of mite feeding behavior have shown that the immatures are more active foragers and feeders compared with the adults (H. S. Melidossian, unpublished data). When actively engaged in feeding, it appears that the tydeids physically damage the fungal thallus by tearing at the mycelia or conidia with their palps. Desiccation and collapse 
of the fungal structure follows as the cellular contents leak out or are ingested by the mite through the stylet. Scanning electron micrographs illustrated the shrunken and desiccated condition of hyphae exposed to feeding by $O$. lambi compared with hyphae that had not been exposed (Fig. 4) $(1,9)$.

In order for $O$. lambi to serve as an effective biological control agent of grapevine powdery mildew in commercial vineyards, either sufficiently dense populations of the mites must be established or existing populations must be maintained. The development of pesticide spray programs that preserve tydeid mite populations while providing adequate suppression of the entire complex of pests and diseases facing the grower (13) is possibly the greatest challenge to commercially relevant suppression of powdery mildew by $O$. lambi. Research by English-Loeb et al. (2) has demonstrated that $O$. lambi is sensitive to the fungicides sulfur and mancozeb and the insecticide carbaryl, but is relatively unaffected by the QoL and DMI fungicides. With the decline in efficacy of the strobilurins and sterol inhibitors in New York State $(16,17)$, many growers are relying more heavily on sulfur applications to control grapevine powdery mildew. Sulfur may be of even greater importance in drier climates where downy mildew and other wet-weather diseases are either of less concern, or are entirely absent (13). However, it is worthwhile to note that the highest levels of disease suppression we obtained using $O$. lambi compared favorably to the level of suppression often reported for sulfur, especially in cooler, higherrainfall climates (17). G. M. English-Loeb (unpublished data) achieved excellent control of foliar powdery mildew in a mixed cultivar vineyard by utilizing several alternatives to sulfur and mancozeb, including captan, fenarimol, and azoxystrobin, in spray programs that conserved populations of $O$. lambi. The costeffectiveness of such a program would likely be site-specific, as the spectrum of diseases to be controlled, local weather, cultivar, intended use of the crop, and the relative efficacy, cost, and required frequency of application for candidate materials would have to be considered.

Although unlikely to provide adequate commercial suppression of powdery mildew on $V$. vinifera cultivars by itself, $O$. lambi could possibly provide a higher level of disease suppression on cultivars of native North American Vitis species, which are more resistant to powdery mildew, and also on certain more mildew-resistant Vitis interspecific hybrid cultivars, as demonstrated by English-Loeb et al. (2). The majority of these cultivars require less intensive fungicide applications. Moreover, as previously noted, sulfur is phytotoxic to some of these cultivars. Finally, O. lambi has been reported to occur naturally on a
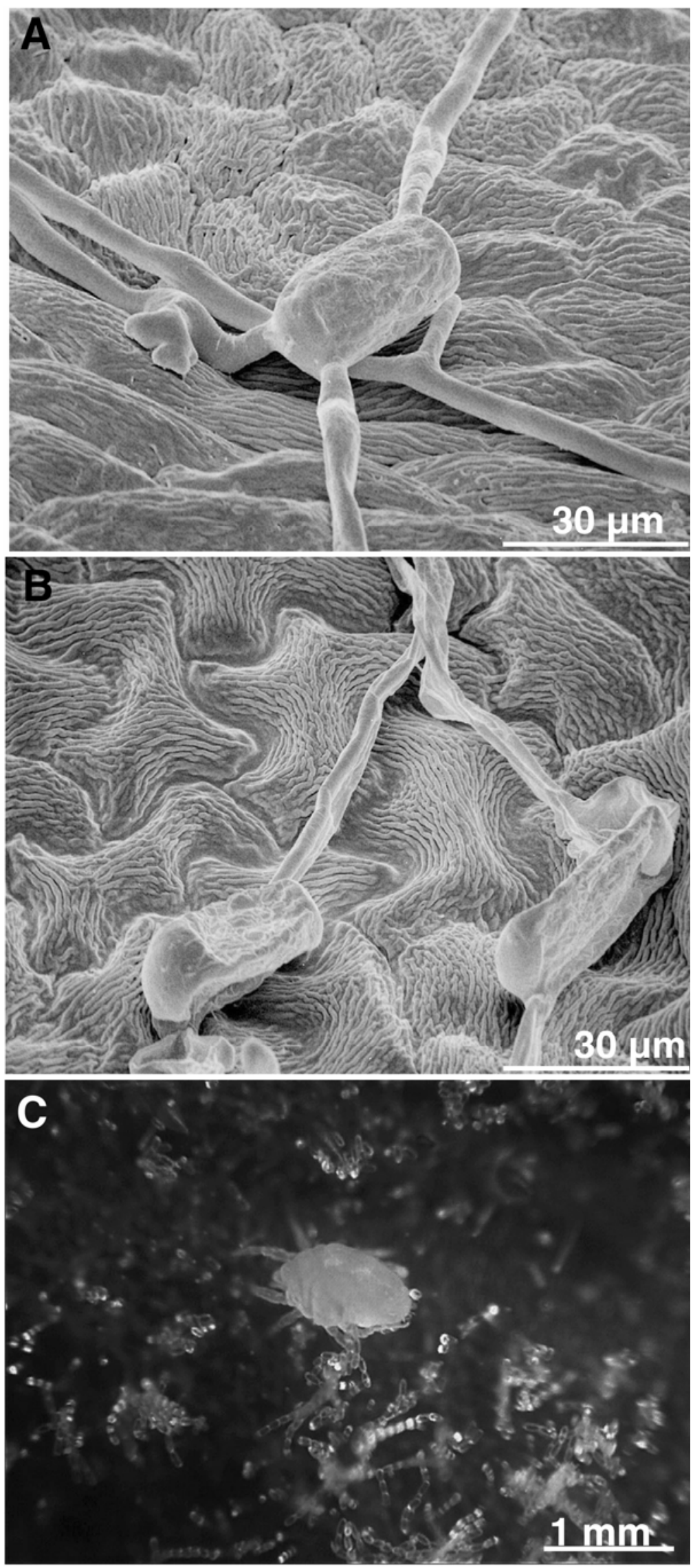

Fig. 4. Micrographs of A, scanning electron microscope (SEM) view of healthy powdery mildew hyphae that were not exposed to Orthotydeus lambi; B, SEM view of desiccated hyphae that were typical of colony is exposed to $O$. lambi; and $\mathbf{C}$, epiluminescence micrograph of $O$. lambi feeding within a sporulating colony of Uncinula necator. 
variety of plant families, and significant suppression of rose and cucumber mildew by $O$. lambi was obtained by A. P. Norton (unpublished data). Our research may serve as a model system for exploitation of $O$. lambi in controlling powdery mildews of diverse plant species.

\section{LITERATURE CITED}

1. Belanger, R. R. and Labbe, C. 2002. Control of Powdery Mildews without Chemicals: Prophylactic and Biological Alternatives for Horticultural Crops. In: The Powdery Mildews, A Comprehensive Treatise. R. R. Belanger, W. R. Bushnell, A. J. Dik, and T. L. W. Carver, eds. American Phytopathological Society, St. Paul, MN.

2. English-Loeb, G. M., Norton, A. P., Gadoury, D. M., Seem, R. C., and Wilcox, W. F. Tritrophic interactions among grapevines, a fungal pathogen, and a mycophagous mite. Ecol. Applic. In press.

3. English-Loeb, G. M., Norton, A. P., Gadoury, D. M., Seem, R. C., and Wilcox, W. F. 1999. Control of powdery mildew in wild and cultivated grapes by a tydeid mite. Biol. Control 14:97-103.

4. Falk, S. P., Gadoury, D. M., Pearson, R. C., and Seem, R. C. 1995. Partial control of grape powdery mildew by the mycoparasite $\mathrm{Am}$ pelomyces quisqualis. Plant Dis. 79:483-490.

5. Ficke, A., Gadoury, D. M., Seem, R. C., and Dry, I. B. 2003. Effects of ontogenic resistance upon establishment and growth of Uncinula necator on grape berries. Phytopathology 93:556-563.

6. Gadoury, D. M., Seem, R. C., Ficke, A., and Wilcox, W. F. 2003. Ontogenic resistance to powdery mildew in grape berries. Phytopathology 93:547-555.

7. Hofstein, R., Daoust, R. A., and Aeschlimann, J. P. 1996. Constraints to the development of biofungicides: The example of "AQ10", a new product for controlling powdery mildews. Entomophaga 41:455-460.

8. Martin, J. E. H. 1977. Collecting, preparing and preserving insects, mites and spiders. Page 182 in: The Insects and Arachnids of Canada, Part 1. Research Branch Canada Department of Agriculture. Publ. 1643.

9. Melidossian, H. M., Seem, R. C., Gadoury, D. M., Wilcox, W. F., and English-Loeb, G. M. 2004. Biological control of Uncinula necator by tydeid mites. (Abstr.) Phytopathology 94:S70.

10. Mendel, Z., and Gerson, U. 1982. Is the mite Lorryia formosa Cooreman (Prostigmata: Tydeidae) a sanitizing agent in citrus groves? Acta 3:47-51.

11. Norton, A. P., English-Loeb, G. M., Gadoury, D. M., and Seem, R. C. 2000. Mycophagous mites and foliar pathogens: Leaf domatia mediate tritrophic interactions in grapes. Ecology 81:490-499.

12. Pearson, R. C., and Gadoury, D. M. 1991. Powdery mildew of grape. Pages 129-146 in: Plant Diseases of International Importance:
Diseases of Fruit Crops, Vol. III. J. Kumar, H S. Chaube, U. S. Singh, and A. N. Mukhopadhyay, eds. Prentice Hall, Englewood Cliffs, NJ.

13. Pearson, R. E., and Goheen, A. C. 1988. Compendium of Grape Diseases. American Phytopathological Society, St. Paul, MN.

14. Walter, D. E., and O'Dowd, D. J. 1995. Life on the forest phylloplane: Hairs, little houses, and myriad mites. Pages 324-352 in: The Forest Canopy: Aspects of Research on this Biological Frontier. M. E. Lowman and N. Nadkarni, eds. Academic Press, New York.

15. Walter, D. E., and Proctor, H. C. 1999. Mites: Ecology, Evolution and Behavior. CABI Publishing Co., Wallingford, Oxon, UK.

16. Wilcox, W. F., Burr, J. A., Riegel, D. G., and Wong, F. P. 2003. Practical resistance to QoI fungicides in New York populations of Uncinula necator associated with quantitative shifts in pathogen sensitivities. (Abstr.) Phytopathology 93:S90.

17. Wilcox, W. F., and Riegel, D. G. 2004. Evaluation of fungicide programs for control of grapevine powdery mildew in a strobilurin resistant site, 2003. Fungic. Nematicide Tests. Rep. 59:SMF011. DOI: 10.1094/FN59.

18. Wong, F. P. 2001. Chemical control of grapevine downy mildew (Plasmopara viticola) and powdery mildew (Uncinula necator): Physical modes of action, resistance monitoring, and evaluation of anti-resistance strategies. Ph.D. thesis. Cornell University, Geneva, NY. 